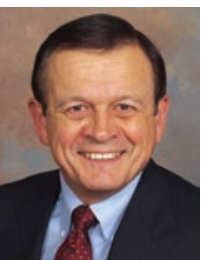

Many researchers view microanalysis as the determination of composition and structure of individual phases at a spatial resolution of $1 \mu \mathrm{m}$ or better. It is remarkable to me that much of what we know about the phases shown in equilibrium phase diagrams was determined using bulk analysis techniques like powder X-ray diffraction in combination with light microscopy of flat-polished sections of materials. The identities and amounts of phases were deduced from systematic experiments because there was no way to analyze micrometer-sized phases in situ.

A breakthrough came in 1951 when Castaing showed that a focused electron beam could generate measurable characteristic $\mathrm{X}$ rays from single-phase regions at a spatial resolution of $1 \mu \mathrm{m}$. This technique may be termed electron probe microanalysis (EPMA) when accomplished in special-purpose instruments or X-ray emission spectrometry (XES) when performed in the scanning electron microscope (SEM). About this same time electron diffraction of thin specimens could provide complementary crystal structure information from crushed sub-micrometer phases analyzed in the transmission electron microscope.

In 1973 Venables and Harland showed that electron diffraction information could be obtained in the SEM from focused electron beams stopped within individual phases of bulk solids. With electronic acquisition of these diffraction patterns and computer-based processing and analysis of the information, this technique developed into the electron backscatter diffraction (EBSD) we know today.

In modern SEMs, XES and EBSD work together to yield quantitative analyses of compositions and crystal structures within sub-micrometer phases. Indeed, X-ray maps of element distributions and maps of crystal grain orientations are key tools for microanalysis investigations in many fields.

The special section in this issue shows that progress in these techniques continues. Hombourger and Outrequin demonstrate that adding a field-emission electron source to an EPMA employing wavelength-dispersive X-ray spectrometers allows high-spatial resolution analysis at low electron beam energies. Geiss et al. explain how high-spatial resolution diffraction data can be obtained in transmission with commercial EBSD detection systems. Finally, Barbi and Mott produce improved correlations of SEM images with XES data by attaching a new design of electron detector to the end of the X-ray detector.

Editor-in-Chief

Charles Lyman

Publication Objective: to provide information of interest to microscopists.

Microscopy Today is a controlled-circulation trade magazine owned by the Microscopy Society of America that is published six times a year in the odd months. Editorial coverage spans all microscopy techniques including light microscopy, scanning probe microscopy, electron microscopy, ion-beam techniques, and the wide range of microanalytical methods. Readers and authors come from both the life sciences and the physical sciences. The typical length of an article is about 2,000 words plus figures and tables; feature articles are longer. Interested authors should consult "Instructions for Contributors" on the Microscopy Today website: www.microscopy-today.com.

\section{ISSN 1551-9295}

\section{Disclaimer}

The Microscopy Society of America and the editors cannot be held responsible for opinions, errors, or for any consequences arising from the use of information contained in Microscopy Today. The appearance of advertising in Microscopy Today does not constitute an endorsement or approval by the Microscopy Society of America of any claims or information found in the advertisements. By submitting a manuscript to Microscopy Today, the author warrants that the article is original or that the author has written permission to use copyrighted material published elsewhere. While the contents of this magazine are believed to be accurate at press time, neither the Microscopy Society of America, the editors, nor the authors can accept legal responsibility for errors or omissions.

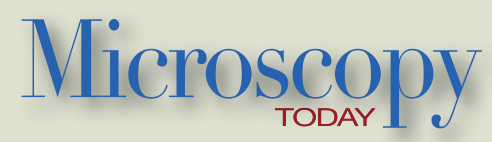

Editorial Staff

Charles E. Lyman, Editor-in-Chief

charles.lyman@lehigh.edu

(610) 758-4249

Gennifer Levey, Production Manager

glevey@meridianartproduction.com

(212) 780-0315

Ron Anderson, Executive Editor microscopytoday@tampabay.rr.com Phil Oshel, Technical Editor oshellpe@cmich.edu

Stephen Carmichael, Columnist carmichael.stephen@mayo.edu

Michael Davidson, Pioneers Editor

davidson@magnet.fsu.edu

Steven Barlow, Education Editor

sbarlow@sunstroke.sdsu.edu

Thomas E. Phillips, Consulting Editor

phillipst@missouri.edu

E. Ann Ellis, Microscopy 101 Editor

eann.ellis@worldnet.att.net

Paul Webster, Calendar Editor

pwebster@usc.edu

John Shields, Humor Editor

jpshield@uga.edu

Thomas Kelly, Chief Awards Judge

Thomas.kelly@ametek.com

Advertising Sales

M.J. Mrvica Associates, Inc.

2 West Taunton Avenue, Berlin, NJ 08009 mjmrvica@mrvica.com

(856) 768-9360

Amy Reuter, Account Manager

areuter@mrvica.com

Magazine website:

http://www.microscopy-today.com

Free subscriptions are available

Publisher

Cambridge University Press

32 Avenue of the Americas

New York, NY 10013-2473

(212) $337-5000$

Circulation: 18,000

Editorial Board

Arlan Benscoter, Lehigh University John Bozzola, Southern Illinois University

Peter Crozier, Arizona State University

Vinayak Dravid, Northwestern University

Joseph Goldstein, University of Massachusetts

David Grubb, Cornell University

Bryan Huey, University of Connecticut

John Mackenzie, North Carolina State Univ.

Paul Maddox, University of Montreal

Ania Majewska, U. Rochester Med School

Greg Meeker, U.S. Geological Survey

Joseph Michael, Sandia National Labs

Caroline Miller, Indiana University

Brian M. Patterson, Los Alamos National Lab

Robert Price, University of South Carolina

John Reffner, John Jay College, SUNY

Ian Robertson, University of Wisconsin

Phillip Russell, Appalachian State University

Glenn Shipley, Citizen Microscopist

Robert Simmons, Georgia State University

Paul Voyles, University of Wisconsin

Simon Watkins, University of Pittsburgh

Cynthia Zeissler, Nat. Inst. of Sci. and Tech. (NIST) 